\title{
Brightness discrimination in reflected laser light
}

L. E. HOGAN, C. L. RUDDER, S. H. LEVINE, and C. L. ASKLAND, JR., Saint Louis Reconnaissance Laboratory, McDonnell Douglas Corporation, St. Louis, Mo. 63166

Brightness discrimination judgments for gray chips were made by 12 male human Ss using the psychophysical method of limits. White, noncoherent red, and He-Ne laser light sources of equal power were used. The data showed poorer discrimination from white to red to laser light and better discrimination when trials started from the darker end of the stimulus range. Results are discussed in terms of human spectral sensitivity, masking effect of the standing diffraction pattern in laser light, and brightness contrast between the stimulus and surround.

A human observer sees scattered laser light as a pattern composed of bright and dark spots. The exact appearance of the pattern is a function of distance from the observer to the scattering surface and relative motion between the observer and the scattering surface. These effects have been described by Oliver (1963) and by Rigden \& Gordon (1962) who attribute them to a random but stationary defraction pattern. The bright spots in the pattern appear in front of the scattering surface. As they are caused by properties of the scattered light and not the viewing system, they always appear in focus. Printed information on the scattering surface behind the spots is defocused and tends to disappear (Oliver, 1963). The research reported here was designed to assess the effects of this phenomenon on brightness discrimination.

The psychophysical method of limits (Guilford, 1955) was chosen because it leads to a numerical expression of a difference limen. The laser source emitted light at $6328 \AA$, well into the red range of the visible spectrum. From the spectral sensitivity curve (see Graham, Ed., 1965) we would predict an increase in the value of the difference limen for red light over that for white light of equal power. In laser light, a further degradation would be predicted from the masking effect of the standing diffraction pattern.

\section{Subjects}

$$
\text { METHOD }
$$

The Ss were 12 adult males with no known visual defects. Apparatus

The $\mathrm{S}$ station was a laboratory stool fitted with a Mackworth camera head frame to provide a rigid, vertical head restraint. The Ss' viewing angle was $90 \mathrm{deg}$ to the stimulus surface. The center of the $S$ station was 200 in. from the face of an $11 \frac{1}{2} \times 6$ in. flat black stimulus mounting frame. Two $2 \frac{1}{4} \times 5$ in. photo paper chips could be viewed simultaneously in side-by-side positions. The chips were produced by projecting an 11-step gray scale (Kodak step Tablet No. 1A) onto Kodak poly-contrast $\mathrm{N}$ semi-matte photographic paper in a photo enlarger. Exposures were at $6 \mathrm{sec}$ intervals from 60 to $120 \mathrm{sec}$ providing a population of 110 gray chips, 18 of which were selected on the basis of MacBeth illuminometer readings and mounted on illustration board.

The values assigned to the gray stimulus chips and the frame are recorded in Table 1 . These values are from the illuminometer scale with the calibration lamp as the light source. Chip zero and the standard chip were approximately equal in value. A spot photometer gave a reading of $6 \mathrm{ft}-\mathrm{L}$ from the standard chip in an ambient illumination producing a reading of $43 \mathrm{ft}-\mathrm{L}$ from a piece of imageless, ferrotyped Kodak Poly-contrast, rapid $F$ photo paper. Three experimental light sources were used: (a) A Spectra Physics Model 125, 75-mW (operated at $60 \mathrm{~mW}$ ) continuous-wave, helium neon laser with
Table 1

Values Assigned to Stimulus Materia

\begin{tabular}{cccccccc}
\hline Chip & Value & Chip & Value & Chip & Value & Chip & Value \\
\hline-8 & 10.55 & -4 & 7.67 & 1 & 4.48 & 5 & 3.86 \\
-7 & 10.13 & -3 & 6.30 & 2 & 4.17 & 6 & 3.50 \\
-6 & 9.70 & -2 & 6.13 & 3 & 4.16 & 7 & 3.22 \\
-5 & 8.70 & -1 & 5.60 & 4 & 3.93 & 8 & 2.96 \\
& & 0 & 5.17 & & & Frame & 3.69 \\
\hline
\end{tabular}

power on the target reduced by a Kodak Wratten 0.90 neutral density filter placed in the beam path and with the beam expanded to cover the stimulus mounting frame from an angle of $30 \mathrm{deg}$; (b) an Ealing Model 22-777 projection illuminator with variable intensity control; (c) same as (b) except with a Kodak F29 red filter placed in the beam to place the light on the target in the red range surrounding $6328 \AA$. Distances, angles, and intensities were equated to provide the same reflectance from the target for all three sources within negligible limits as measured by a Gossen lightmeter. The experimental room was essentially light tight. Reflected power from the target surface toward the eye was approximately 0.3 $\mathrm{mW}$.

Procedure

The Ss were dark adapted for $15 \mathrm{~min}$. The standard chip was then placed in one side of the frame and the first light source was turned on. A comparison chip was placed in the other side and $\mathbf{S}$ was required to judge the chips to be "same," "lighter," or "darker" and to then close his eyes until another judgment was called for. A trial lasted until the $S$ judged "same" or until he judged "darker" when a series of judgments started from the lighter end of the range or "lighter" when starting from the darker end. The score for a trial was the number of the chip ending that trial. The $S$ was told to keep his eyes closed after the 10th trial while the second light source was set up. At the end of 10 more trials, this procedure was repeated while the third light source was set up for another 10 trials. Position of standard chip (left or right). order of presentation of the three light sources, and lighter or darker starting point were all counterbalanced. No two successive lighter or darker trials started with the same comparison chip.

\section{RESULTS}

The first two trials for each $\mathrm{S}$ in each light were discarded to eliminate effects associated with orienting to the experimental situations. Results are then based on eight trials (four each up, down, left, right, or two each for any combination of L-R, U-D for each of three lights for $12 \mathrm{Ss}$ ). There were, therefore, 288 terminal responses in the experiment. The number of judgments per trial was in the range of one to nine, depending on the starting point in the stimulus series. The average $S$ made more than 100 judgments. Table 2 shows the data produced by the $S s$ and indicates difference limens for the three experimental conditions.

Table 2 Calculation of Difference Limens

\begin{tabular}{lrrrlrrr}
\hline & L & R & W & & L & R & W \\
\hline UP & -2.375 & -2.020 & -1.270 & UP & -1.890 & -1.400 & -1.000 \\
DN & 1.375 & 0.600 & 0.040 & DN & 1.910 & 1.300 & 0.270 \\
DL & 1.875 & 1.310 & 0.650 & DL & 1.900 & 1.350 & 0.635 \\
\hline \multicolumn{3}{c}{ Standard Chip Left } & & \multicolumn{3}{c}{ Standard Chip Right } \\
\hline
\end{tabular}


Table 3

Distribution of "Same" Responses

$\begin{array}{llllllllllllll}\text { Frequency } & 1 & 2 & 8 & 40 & 25 & 58 & 57 & 30 & 18 & 12 & 13 & 5 & 1\end{array}$

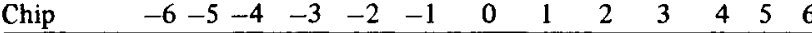

Each point in the table was calculated from the average of 24 trials. A difference limen is indicated for each of the six pairs of approaches to the line of symmetry. These values are unique to the stimulus material, illumination levels, viewing angle, and experimental situation. Of much more interest are the trends which are present in the table. An analysis of variance produced $F$ ratios of 14.03 for the effect of lights (df $=2,22, \quad p>.01)$ and 34.69 for the up-down effect (df $=1,22, p>.01)$.

To assess the magnitude of the up-down effect, Table 3 was constructed by making a frequency distribution of the values of the 271 "same" terminal responses. Of the 17 responses which created half steps (called lighter rather than same when starting from dark end of range and vice versa) seven were $+1 / 2$ step, seven were $-1 / 2$ step, and the remaining three were greater than $-1 \frac{1}{2}$ steps. Table 3 shows the magnitude and direction of the up-down effect in the skew of the distribution of judgments.

In summary, our results show that the size of a difference limen for gray increases as we vary the illumination source from white, to red, to laser light and that it tends to be smaller when starting judgment trials from the darker rather than the lighter end of the stimulus range.

\section{Discussion}

We explain the observed up-down effect in terms of the black color of the stimulus mounting frame. In any series of judgments on a down trial, $S$ had an opportunity to observe the comparison chip depart from near the color of its surround by small increments to the same target-surround brightness contrast exhibited by the standard chip and the stimulus frame. On up trials, $S$ observed an initially high targetsurround contrast which decreased by small increments toward a lower contrast level. We feel this condition made judgments easier on down trials. The observed degradation in the brightness discrimination abilities of our Ss from white to red to laser light matches our predictions in regard to the effects of the spectral sensitivity of the eye and the masking effect of the standing diffraction pattern. The magnitude of the differences among difference limens reflects the magnitude of this effect under the experimental conditions.

\section{REFERENCES}

GRAHAM, C. (Ed.), Vision and visual perception. New York: Wiley \& Sons, Inc., 1965.

GUILFORD, J. P. Psychometric methods. New York: McGraw-Hill, 1955. OLIVER, B. Proc., IEEE (Correspondence), Vol. 51, p. 220, Jànuary, 1963.

RIGDEN, J. B., \& GORDON, E. L. Proc., IRE (Correspondence), Vol. 50, p. 2367, November, 1962.

NOTE

1. C. L. Askland is now at St. Cloud State College, St. Cloud, Minnesota.

(Continued from page 264)

Table 2

Latency Means (in seconds) for Each Group and Phase

\begin{tabular}{|c|c|c|c|c|c|c|c|}
\hline & \multicolumn{6}{|c|}{ Group } \\
\hline & & 1 & 2 & 3 & 4 & 5 & 6 \\
\hline Phase & 1 & $12.83(\mathrm{NP})$ & $12.74(\mathrm{NP})$ & $20.02(\mathrm{FL})$ & $21.97(\mathrm{SH})$ & $22.01(\mathrm{FL})$ & $21.52(\mathrm{SH})$ \\
\hline & 2 & $22.98(\mathrm{FL})$ & $25.23(\mathrm{SH})$ & 13.04(FL) & $13.18(\mathrm{SH})$ & $15.34(\mathrm{SH})$ & $15.01(\mathrm{FL})$ \\
\hline
\end{tabular}

\section{RESULTS}

Latency means (the time in seconds between slide onset and the first response) for each group and phase are presented in Table 2.

One latency mean was obtained for each $\mathrm{S}$ in each group for the first set of six problems (Phase 1). The group effect was significant $[F(5,54)=2.73, p<.05]$. By Neuman-Keuls comparisons NP groups each answered faster than any other group $(\mathrm{p}<.05)$.

One latency mean was obtained for each $\mathrm{S}$ in each group for the final set of six problems (Phase 2). The group effect was significant $[F(5,54)=6.15, p<.005]$. By Neuman-Keuls comparisons Group $1(\mathrm{FL})$ or $2(\mathrm{SH})$ took longer to answer than any other group $(\mathrm{p}<.05)$.

\section{DISCUSSION}

The finding that each NP group (Phase 1) answered faster than any other group agrees with the pilot study where it was determined that FL or SH was a punishing stimulus.

The finding that in Phase 2 Group 1(FL) took longer to answer than Group 3(FL), and Group 2(SH) took longer to answer than Group 4(SH) agrees with studies involving animal Ss (e.g., Azrin, 1960) and supported the first prediction that experience with a particular punishment renders individuals less sensitive to further presentations of this punishment.
The finding that in Phase 2, Group 1(FL) took longer to answer than Group 6(FL), and Group 2(SH) took longer to answer than Group 5(SH) also agrees with studies involving animal Ss (e.g., Terris \& Wechkin, 1967) and supported the second prediction that experience with a particular punishing stimulus renders individuals less sensitive to a novel punishment.

It would appear that human Ss respond to continued punishing stimulation as do some infrahuman organisms.

\section{REFERENCES}

AZRIN, N. H. Sequential effects of punishment. Science, 1960, 131, 605-606.

HAKE, D. F., \& AZRIN, N. H. An apparatus for delivering pain-shock to monkeys. Journal of the Experimental Analysis of Behavior, 1963, 6, 297-298.

HOLZ, W. C., \& AZRIN, N. H. Recovery during punishment by intense noise. Psychological Reports, 1962, 11, 655-657.

SKINNER, B. F. The behavior of organisms. New York: AppletonCentury-Crofts, 1938.

TERRIS, W., \& WECHKIN, S. Learning to resist the effects of punishment. Psychonomic Science, 1967, 7, 169-170. NOTES

1. Adapted from a Masters thesis submitted in partial fulfillment of the requirements for the degree of Master of Science.

2. Now a Ph.D. student at the Department of Psychology, Queen's University, Kingston, Ontario, Canada. 